\title{
Universiteit
}

Leiden

The Netherlands

\section{Cantonese as a tense second language}

Cheng, L.L.; Zwart, C.J.W.; Vries, M. de

\section{Citation}

Cheng, L. L. (2010). Cantonese as a tense second language. In C. J. W. Zwart \& M. de Vries (Eds.), Linguistik Aktuell/Linguistics Today (pp. 73-79). Amsterdam: John Benjamins Publishing Company. doi:10.1075/la.164.09che

Version:

Publisher's Version

License:

Licensed under Article 25fa Copyright Act/Law (Amendment Taverne)

Downloaded from: $\quad$ https://hdl.handle.net/1887/3245411

Note: To cite this publication please use the final published version (if applicable). 


\title{
Cantonese as a tense second language
}

\author{
Lisa Lai-Shen Cheng \\ Leiden University
}

\section{Introduction}

Koster (2003) re-examines verb second properties and addresses the question of why verbs undergo movement to the $\mathrm{C}^{0}$ position. He proposes to align verb movement with other movements, in particular, wh-movement, in their underlying reason for movement, namely, in highlighting salient information as well as in signalling scope (cf. Evers (1982) and Pollock (1989)). He further argues that the scope information that verb movement is connected to is Tense. In other words, Verb Second movement (i.e. $\mathrm{V}^{0}$ to $\mathrm{C}^{0}$ movement) is marking Tense in second position (i.e. Tense in $\mathrm{C}^{0}$ ).

He ends the paper by speculating that all languages (not just English and Germanic languages) are subject to the following Tense Second Constraint:

(1) Tense Second Constraint

All languages mark Tense/Type in the "second" position (C) of the main clause.

In this paper, I venture to argue that Cantonese, a language which on the surface seems to be the counterexample for (1) as a universal constraint, is in fact a Tense Second language. In Section 1.1, I summarize the core ingredients of Koster's (2003) proposal. In Section 2, I discuss Tense in Cantonese, both in the T-domain and in the C-domain. Section 3 examines some technicalities concerning the clause structure in Cantonese, and concludes that Cantonese is a Tense Second language.

\subsection{Core ingredients}

There are a couple of core ingredients in Koster's proposal that need to be highlighted in order to understand and appreciate his proposal. First, complementizers do not only code clause type information, but also Tense/finiteness information (see den Besten 1977). And $C^{0}$ in main clauses also has the same encoding, with $V^{0}$ to $C^{0}$ movement contributing to Tense encoding in $\mathrm{C}^{0}$, while clausal typing in the case of declarative sentences remain mostly unmarked (or by ø-marking). Second, in English and Germanic languages, when $\mathrm{V}^{0}$ stays in-situ, it is because (a) the $\mathrm{C}^{0}$ position is already filled, albeit by a $\varnothing$-marker, and (b) the Infl position is either filled by $\emptyset$-auxiliary element (in English), or it is absent (or emptied out) (e.g. in Dutch). 
Furthermore, Koster (2003) makes a very interesting parallel between $w h$-movement and verb movement - wh-movement allows "partial"-movement with a scope marker filling the scope marker position (and in some languages like Malay, it can be null). That verbs may stay lower than $\mathrm{C}^{0}$ can be viewed as "partial"-movement cases of $\mathrm{V}^{0}$ to $\mathrm{C}^{0}$ movement, with the higher (null) element occupying the $\mathrm{C}^{0}$ or $\mathrm{T}^{0}$ position. In sum, verbs do not have to be positioned in $\mathrm{C}^{0}$ in overt syntax to satisfy the constraint in (1). They can be in $\mathrm{T}^{0}$ or $\mathrm{C}^{0}$ depending on the materials in $\mathrm{T}^{0}$ or $\mathrm{C}^{0}$.

\section{Cantonese}

It is often claimed or assumed that Chinese languages have no Tense, and thus no TenseP (see Lin 2006 for arguing that there is Tense, but no TenseP in Chinese). This is basically because there is no tense marker or tense inflection of the type we find in Indo-European languages. To illustrate that Cantonese is actually a Tense Second language, we not only have to show that there is a Tense node, we also need to show that the C-node has something to do with Tense. In this section, I first briefly summarize some of the arguments provided in Sybesma $(2004,2007)$ for a Tense-node in Chinese. I then discuss sentence final particles, which are the best candidates for realizing a C-node.

Consider first the Tense node. First, though Chinese languages do not have morphological or grammaticalized means to mark past events, and temporal adverbs are used to distinguish past versus current events ((2a) vs. (2b)), it should be noted that (2b) is interpreted as a present event without any context, and that the temporal reading of (2b) can only be changed by using linguistic material (e.g. by the addition of an adverb such as $j i^{5}-\mathrm{cin}^{4}$ 'before' in (2a)) (examples from Sybesma 2004).

(2) a. $\mathrm{keoi}^{5} \mathrm{ji}^{5}-\mathrm{cin}^{4} \mathrm{hai}^{2}$ Rotterdam $\mathrm{zyu}^{6}$

$3 \mathrm{~s}$ before at Rotterdam live

'S/he used to live in Rotterdam.'

b. $\mathrm{keoi}^{5} \mathrm{hai}^{2}$ Rotterdam $\mathrm{zyu}^{6}$

$3 \mathrm{~s}$ at Rotterdam live

'S/he lives in Rotterdam.'

These suggest that the temporal interpretation does not only come from contexts, and most likely due to the presence of a Tense node. (3) and (4) make a similar argument as the examples in (2) (examples in (4) are adapted from Sybesma 2007). Note that in Dutch, the Tense morpheme on the verb woonde 'live.PsT' cannot express past events without the temporal adverb in 1989. This is similar to the Cantonese examples in (2) and (3). 
(3) a. $\mathrm{ngo}^{5} \mathrm{hai}^{2}$ Rotterdam $\mathrm{zyu}^{6}$

$1 \mathrm{~s}$ in Rotterdam live

'I live in Rotterdam.'

₹ 'I lived in Rotterdam.' (past tense)

b. ngo $^{5}$ 1989-nin ${ }^{4}$ hai $^{2}$ Rotterdam zyu $^{6}$

1s 1989-year in Rotterdam live

'I lived in Rotterdam in 1989.'

(4) a. Ik woon in Rotterdam.

1s live in Rotterdam

'I live in Rotterdam.'

b. Ik woonde ${ }^{*}$ (in 1989) in Rotterdam.

1s live.PST in 1989 in Rotterdam

'I lived in Rotterdam in 1989.'

Sybesma (2007) thus argues that Dutch and Mandarin are actually the same in their use of Tense. What is needed in (3) and (4) is agreement with a temporal adverb in the case of past events. It is suggested that Dutch Tense morphemes are actually agreement morphemes; and what Mandarin lacks is not a Tense node, but rather an overt (Tense) agreement morpheme.

Let us now turn to the C-node. Arguments using complementizers (which determine the finiteness and thus tense) of the embedded clause cannot be used in languages like Cantonese, since there are no complementizers of the type in English and Dutch (see Hsieh \& Sybesma 2007). Sybesma (2004), assuming that there is a Tense operator in the $\mathrm{C}$-domain, which binds a pronominal variable in the T-domain, proposes that certain elements in Cantonese are realizations of such Tense operators (in the C-domain). The elements in question are the so-called sentence-final particles, in particular $l e i^{4}$ and $g e^{3}$. Consider first $l e i^{4}$.

(5) a. keoi $^{5}\left(1989 \operatorname{nin}^{4}\right)$ hai $^{2}$ Rotterdam $\mathrm{zyu}^{6} \mathrm{lei}^{4}$

3s 1989 year at Rotterdam live LEI $^{4}$

'(In 1989) s/he lived in Rotterdam for a while.' (adapted from Sybesma 2004)

b. keoi $^{5} \mathrm{da}^{2}-\mathrm{bo}^{1} \mathrm{lei}^{4}$

3s hit-ball LEI $^{4}$

'He was (just) playing ball.'

$\mathrm{Lei}^{4}$ in (5a) has an interpretation quite similar to the experiential marker $g w o^{3}$ in Cantonese, or guò in Mandarin. (5a) means that he or she lived in Rotterdam for a while and if 1989 is added, it means that during that year, he or she lived in Rotterdam for a while (i.e. not necessarily the whole year (most probably not)). However, $l e i^{4}$ in (5b) does not have an interpretation similar to the experiential marker (see also (6) below where $l e i^{4}$ co-occurs with the experiential marker $g w o^{3}$ ). Rather, the sentence can be 
a response to questions such as: 'why is he/she sweating so much?' or 'why is he/she so tired?' It clearly indicates a past event, and it can be a recent past or a remote past. Note further that with the presence of $l e i^{4}$, neither (5a) (without 1989), nor (5b) can have a non-past interpretation. In other words, $l e i^{4}$ can be considered to have a feature [+past].

Note that $l e i^{4}$ is not an aspectual marker attached to the verb. (6) illustrates this very clearly, since $l e i^{4}$ in (6) appears after an indirect object. Thus, we can safely conclude that the sentence 'final' element $l e i^{4}$ is [+past] (and we will come back to the question of why sentence final particles are considered to be in $\mathrm{C}^{0}$ ).

(6) $\mathrm{ngo}^{5} \mathrm{kam}^{4}-\mathrm{jat}^{6} \mathrm{da}^{2}-\mathrm{gwo}^{3} \quad \mathrm{din}^{6}-\mathrm{wa}^{2} \quad \mathrm{bei}^{2} \mathrm{lei}^{5} \quad \mathrm{lei}^{4}$ 1s yesterday hit-EXP telephone give you $\mathrm{LEI}^{4}$ 'I called you yesterday'.

Let us now turn to $g e^{3}$, which has been called an assertion marker (Cheung 1972) or an actuality marker (Sybesma 2004). This can be seen from (7) (comparing with (5b)).

(7) $\mathrm{keoi}^{5} \mathrm{da}^{2}-\mathrm{bo}^{1} \mathrm{ge}^{3}$

3s hit-ball $\mathrm{GE}^{3}$

'He is a ball-player.'

(7) essentially asserts that he plays ball (and in this sense, he is a ball-player), and it can also be interpreted as relevant to the current context (i.e. its actuality function), if it is used as extra information about his physical condition, etc. Consider now (8) and (9).

(8) a. $\mathrm{ngo}^{5} \mathrm{hai}^{2}$ Rotterdam $\mathrm{zyu}^{6} \mathrm{ge}^{3}$

$1 \mathrm{~s}$ in Rotterdam live $\mathrm{GE}^{3}$

'I live in Rotterdam.'

b. $\mathrm{ngo}^{5} \mathrm{ji}^{5}$-cin ${ }^{4} \mathrm{hai}^{2}$ Rotterdam $\mathrm{zyu}^{6} \mathrm{ge}^{3}$

1s before in Rotterdam live $\mathrm{GE}^{3}$

'I lived in Rotterdam before.'

(9) a. keoi ${ }^{5}$ heoi $^{3}-$ gwo $^{3}$ Leiden $\mathrm{ge}^{3}$

3s go-EXP Leiden $\mathrm{GE}^{3}$

'S/he has been to Leiden before.'

b. keoi $^{5}$ mei $^{6} \quad$ sik $^{6}-$ gwo $^{3}$ sushi ge ${ }^{3}$

$3 \mathrm{~s}$ not.yet eat-EXP sushi $\mathrm{GE}^{3}$

'S/he has not eaten sushi before.'

From (8) and (9), one might conclude that $g e^{3}$ is compatible with both past and non-past events. However, it should be noted that in (8) and (9), $g e^{3}$ is either asserting the truth of the statements (cf. de in Mandarin, see Cheng 2008), or making the statement relevant to the current context. Compare (8), and (9) with (10) and (11) 
below. The latter sentences show that $g e^{3}$ is not compatible with episodic events in the past.
a. $\mathrm{keoi}^{5} \mathrm{zou}^{6}-\mathrm{saai}^{3} \mathrm{di}^{1}$ gong ${ }^{1}-\mathrm{fo}^{3} \quad\left({ }^{*} \mathrm{ge}^{3}\right)$
3s do-finish CL homework GE3
'S/he finished doing the homework.'

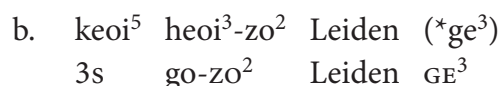
'S/he went to Leiden.'
(11) $\mathrm{keoi}^{5} \mathrm{mou}^{5} \quad \mathrm{da}^{2} \quad \mathrm{din}^{6}-\mathrm{wa}^{2} \quad \mathrm{bei}^{2} \quad \mathrm{lei}^{5} \quad\left({ }^{*} \mathrm{ge}^{3}\right)$
$3 \mathrm{~s}$ not.have hit telephone give you $\mathrm{GE}^{3}$
'S/he didn't call you.'

(10a) and (10b) involve telic events. What (10) and (11) share, in contrast with (8) and (9) is that the former concerns episodic events while the latter does not. Thus, it appears to be the case that $g e^{3}$ is restricted to current events, or non-episodic events in the past.

In sum, though Cantonese does not have Tense morphemes, it arguably has a Tense node, as well as peripheral elements, such as $l e i^{4}$ and $g e^{3}$ (possibly $\mathrm{C}^{0}$-elements) which carry Tense information.

\section{C-domain in Cantonese}

If what I have shown above is on the right track, that is, not only does Cantonese have Tense (and a T-node), the sentence final particles also have Tense-features, a couple of steps are needed before we can claim that Cantonese is a Tense Second language à la Koster (2003).

The first step concerns the position of the sentence final particles such as $l e i^{4}$ and $g e^{3}$. Various linguists in the past have claimed that (some) sentence final particles in Mandarin are in $\mathrm{C}^{0}$ (see e.g. Cheng 1986 for de in Mandarin as $\mathrm{C}^{0}$, see also Gasde \& Paul (1996) as well as Li (2006)). Sybesma \& Li (2007) present a more elaborate left periphery for Cantonese sentence-final particles and show how the co-occurrence of the particles can be represented in the tree structure. If we look closely at the sentence final particles as well as the role of the C-system in the clausal structure, it is most natural to consider the sentence final particles to take part in the C-system. Rizzi (1997) notes that the C-system expresses two kinds of information, one facing outside (e.g. Clause Type/Force), and one facing inside (e.g. relating to the content in the IP, such as Tense). We have seen above that sentence final particles have Tense information. As for Clause types, since Cantonese, like other Chinese languages, does not have overt 
wh-movement, the null hypothesis is that Clause types are marked by typing particles, even though sometimes the particles are non-overt (see Cheng 1991). (12a,b) illustrate overt typing particles in Cantonese.
a. $\mathrm{keoi}^{5} \mathrm{da}^{2}-\mathrm{gwo}^{3} \mathrm{din}^{6}-\mathrm{wa}^{2} \mathrm{bei}^{2} \quad \mathrm{lei}^{5} \mathrm{me}^{1}$
3s hit-EXP telephone give you $\mathrm{ME}^{1}$
'Did s/he call you?'
b. keoi $^{5}$ heoi ${ }^{3}-\mathrm{zo}^{2}$ Leiden $\mathrm{aa}^{4}$
3s go- $\mathrm{ZO}^{2}$ Leiden $\mathrm{AA}^{4}$
'Did s/he go to Leiden?'

(12a) and (12b) show that both $m e^{1}$ and $a a^{4}$ mark the sentence as a yes-no question (see Sybesma \& Li (2007) for more discussion concerning these particles). Without the particles, the sentences are declarative sentences.

Thus, Cantonese sentence final particles have the function of typical elements in the C-system. They not only provide Tense information (i.e. information facing inside), but also provide Clause Type/Force information (i.e. information facing outside). I speculate that it is not the case that only $l e i^{4}$ and $g e^{3}$ in Cantonese carry tense information, rather all $\mathrm{C}^{0} \mathrm{~s}$ in Cantonese have a tense feature (some may have ø-markers). This, however, does not imply that all sentence final particles carry tense information. In Sybesma \& Li (2007), sentence final particles occupy various positions in the left periphery of the main clause (i.e. different C-like heads), it is thus most likely the case that not all overt sentence final particles carry tense features. Which ones do carry such information is open for future research.

One last question that arises concerning the sentence final particles in Cantonese, assuming that they are positioned in $\mathrm{C}^{0}$, is why the $\mathrm{C}^{0}$-element in Cantonese appears to the right of the sentence (i.e. at final position). Though this is not pertinent to the Tense Second claim, it is still important to address the question of whether $\mathrm{C}^{0}$ in Cantonese is head-final (though the rest of the language does not show head-finality). I assume here, following Sybesma (1999) and Hsieh \& Sybesma (2007), that $C^{0}$-elements are base-generated head-initially; they appear final as a result of the TP moving to SpecCP (see the papers mentioned above for different motivations for the TP to SpecCP movement).

To conclude, as mentioned in (1), Koster (2003) claims that all languages mark Tense/Clause Type in the $\mathrm{C}^{0}$ position of the main clause. I mentioned in the introduction that Cantonese on the surface is the counterexample to such a claim. I have shown above that the $\mathrm{C}$-node in Cantonese is occupied by (covert) Tense-related sentence final particles such as $l e i^{4}$ and $g e^{3}$, and that the Tense-node is occupied by a $\varnothing$-marker which agrees with temporal adverbs. Thus, the $\mathrm{C}$-node in Cantonese also allows the language to mark Tense/Clause Type in the $\mathrm{C}^{0}$ position of the main clause. In other words, Cantonese is only an apparent counterexample to the Tense Second Constraint. 


\section{References}

den Besten, Hans den. 1977 [1983]. On the interaction of root transformations and lexical deletive rules. In Werner Abraham (ed.), On the formal syntax of the Westgermania [Linguistik Aktuell/Linguisics Today 3], 47-131. Amsterdam: John Benjamins.

Cheng, Lisa L.-S. 1986. De in Mandarin Chinese. Canadian Journal of Linguistics 31: 313-326.

Cheng, Lisa L.-S. 1991. On the typology of wh-questions. Ph.D. dissertation, MIT.

Cheng, Lisa L.-S. 2008. Deconstructing the shi...de construction. The Linguistic Review 25: 235-266.

Cheung, Samuel H.-N. 1972. Cantonese as spoken in Hong Kong. Hong Kong: The Chinese University of Hong Kong.

Evers, Arnold. 1982. Twee functionele principes voor de regel "Verschuif het Werkwoord". GLOT 5: 11-30.

Gasde, Horst-Dieter \& Paul, Waltraud. 1996. Functional categories, topic prominence and complex sentences in Mandarin Chinese. Linguistics 34: 263-294.

Hsieh, Feng-Fan \& Sybesma, Rint. 2007. On the linearization of Chinese sentence final particles: Max spell out and why CP moves. Ms, Tsing-Hua University and Leiden University.

Koster, Jan. 2003. All languages are tense second. In Jan Koster \& Henk van Riemsdijk (eds.), Germania et alia: A linguistic Webschrift for Hans den Besten. 〈http://www.let.rug.nl/koster/DenBesten/contents.htm〉.

Li, Boya. 2006. Chinese final particles and the syntax of the periphery. Ph.D. dissertation, Leiden University.

Lin, Jo-Wang. 2006. Time in a language without tense: The case of Chinese. Journal of Semantics 23: 1-53.

Pollock, Jean-Yves. 1989. Verb movement, Universal Grammar, and the structure of IP. Linguistics Inquiry 20: 365-424.

Rizzi, Luigi. 1997. The fine structure of the left periphery. In Liliane Haegeman (ed.), Elements of grammar: Handbook of generative syntax, 281-337. Dordrecht: Kluwer.

Sybesma, Rint. 1999. Overth wh-movement in Chinese and the structure of CP. In H. Samuel Wang, Tsao Feng-fu \& Lien Chin-fa (eds.), Selected papers from the Fifth International Conference of Chinese Linguistics, 279-299. Taipei: The Crane Publishing.

Sybesma, Rint. 2004. Exploring Cantonese tense. In Leonie Cornips \& Jenny Doetjes (eds.), Linguistics in the Netherlands 2004, 169-180. Amsterdam: John Benjamins.

Sybesma, Rint. 2007. Whether we Tense-agree overtly or not. Linguistic Inquiry 38(3): 580-587.

Sybesma, Rint \& Boya Li. 2007. The dissection and structural mapping of Cantonese sentence final particles. Lingua 117: 1739-1783. 